\title{
Does research into medical education on tobacco and alcohol get the respect it deserves?
}

\author{
Tobias Raupach ${ }^{1,2}$ \\ Henning Krampe ${ }^{3}$ \\ Jamie Brown ${ }^{2}$
}

\section{Affiliations}

${ }^{1}$ Department of Cardiology and Pneumology, University Hospital Göttingen

Göttingen, Germany

${ }^{2}$ Cancer Research UK Health Behaviour Research Centre, University College London, London, UK

${ }^{3}$ Department of Anesthesiology and Intensive Care Medicine, Campus Virchow Klinikum and Campus Charité Mitte; Charité - Universitätsmedizin Berlin, Germany

Word count

791

Correspondence:

Key words: research, journal, impact, smoking, medical education, policy 
Implementation of effective clinical interventions as part of routine medical care to combat problem drinking and tobacco use is recognised to be low. Insufficient training is an important barrier preventing physicians from delivering interventions recommended in current guidelines. High-impact medical journals publish almost nothing on how to address this. If they start to take an interest perhaps we will see more progress and many thousands of lives saved at minimal cost.

Recent major publications have shown that smoking and problem drinking remain among the most important preventable causes of morbidity and premature death globally (1-5). Combating these has been declared a high priority by the WHO in preventing morbidity and disability from non-communicable disease worldwide (6).

Article 14 of the WHO Framework Convention on Tobacco Control (7) requires signatories to implement programmes to promote smoking cessation and include the diagnosis and treatment of tobacco dependence in national health and education programmes. However, recent research suggests that these goals are not met in many countries (8). For example, Germany ratified FCTC in December 2004, and yet only a minority of patients hospitalised for cardiovascular disease receive advice on how to quit (9). A similar failure has been reported for the primary healthcare sector, and a lack of training appears to be a major barrier preventing physicians from helping smokers quit (10).

In 2010, the World Health Assembly (WHA) endorsed a global strategy aimed at reducing the harmful use of alcohol which also included the implementation of therapy programmes for patients with alcohol use disorders (11). However, a recent WHO survey in 147 countries from all over the world found that the majority of countries report a substantial unmet need for treatment of people with alcohol use disorders (12).

Given that there are effective medical interventions that can be delivered with relatively little training to combat both smoking $(13,14)$ and problem drinking $(15)$ perhaps major medical journals would be as interested in research on the failure of medical education to equip future physicians with counselling skills as in epidemiological studies linking smoking and problem drinking to morbidity and mortality. Or perhaps not. We carried out a PubMed search (date: $1 / 7 / 2013$ ) of the four high-impact general medical journals (BMJ, Lancet, NEJM \& JAMA). During the past 10 years, over 50,000 items were published in these journals. Restricting the search to articles related to 'smoking', 'tobacco', 'alcohol' or 'problem drinking' resulted in just 
over 2,000 hits. Adding the terms 'medical education' or 'medical school' to this search yielded 121 articles, 60 of which presented original research findings. According to the information provided in the abstracts, the majority of articles did not have a primary focus on smoking cessation or problem drinking, and a considerable number addressed epidemiological issues unrelated to medical education. None assessed the extent to which the clinical management of smokers was covered in undergraduate medical curricula. One paper presented the results of a longitudinal cohort study of students at 16 U.S. medical schools. It found that 'extensive training in alcohol counselling was associated with over twice the odds of a final year student's belief that alcohol counselling would be relevant to their practice (...) and reporting that they often counselled patients about their alcohol consumption' (16) which is in line with recent findings from Germany $(17,18)$. There were no evaluations of interventions aimed at addressing this major implementation problem.

High-quality research on how to implement educational interventions aimed at improving counselling skills is readily available (19) but its reach is largely limited to readers with a particular interest in medical education. Unless a more general medical audience takes notice of current shortcomings in medical training and focuses on how to overcome them, change is unlikely to occur.

In addition to providing healthcare professionals with reliable information on recent developments in clinical medicine, high-impact medical journals also serve the general public in that important papers are usually accompanied by highly visible media coverage. Thus, highimpact journals are in a position to increase public awareness and stimulate discussion about critical healthcare issues. Editorial decisions to publish or reject a manuscript therefore need to reflect the responsibility of the research community to support policymakers in making informed choices.

The ultimate goal of medical research is to improve patient outcomes. In the light of the most recent high-impact publications on the health hazards of smoking and problem-drinking, we propose a re-balancing of priorities in favour of research examining the failure of medical education to enable physicians to change the behaviour of their patients and identifying educational interventions that provide effective training. The impact on patient outcomes to be expected from this shift towards preventive medicine would compare favourably to the impact of randomised trials on the treatment of diseases caused by smoking and drinking. 


\section{Declarations of interest}

TR has received honoraria from Pfizer $^{\circledR}$, Novartis ${ }^{\circledR}$, Glaxo Smith Kline ${ }^{\circledR}$, Astra Zeneca ${ }^{\circledR}$, Roche $^{\circledR}$ and Almirall ${ }^{\circledR}$ as a speaker in activities related to continuing medical education and smoking cessation. JB has received an unrestricted research grant from Pfizer $^{\circledR}$. 


\section{References}

1. Pirie, K., Peto, R., Reeves, G. K., Green, J. \& Beral, V. (2013) The 21st century hazards of smoking and benefits of stopping: a prospective study of one million women in the UK, Lancet, 381, 133-41.

2. Jha, P., RAmasundarahetTige, C., LANDSMAn, V. et al. (2013) 21st-century hazards of smoking and benefits of cessation in the United States, $N$ Engl J Med, 368, 341-50.

3. Thun, M. J., CARTER, B. D., FesKaniCh, D. et al. (2013) 50-year trends in smokingrelated mortality in the United States, $N$ Engl J Med, 368, 351-64.

4. TomkIns, S., Collier, T., ORALOV, A. et al. (2012) Hazardous alcohol consumption is a major factor in male premature mortality in a typical Russian city: prospective cohort study 2003-2009, PLoS One, 7, e30274.

5. IKEDA, N., INOUE, M., Iso, H. et al. (2012) Adult mortality attributable to preventable risk factors for non-communicable diseases and injuries in Japan: a comparative risk assessment, PLoS Med, 9, e1001160.

6. Beaglehole, R., Bonita, R., Horton, R. et al. (2011) Priority actions for the noncommunicable disease crisis, Lancet, 377, 1438-47.

7. (2003) WHO Framework Convention on Tobacco Control (Geneva, World Health Organization).

8. Kotseva, K., Wood, D., De Backer, G. et al. (2009) Cardiovascular prevention guidelines in daily practice: a comparison of EUROASPIRE I, II, and III surveys in eight European countries, Lancet, 373, 929-40.

9. Raupach, T., FalK, J., Vangeli, E. et al. (2012) Structured smoking cessation training for health professionals on cardiology wards: a prospective study, Eur J Prev Cardiol.

10. Twardella, D. \& BRENNER, H. (2005) Lack of training as a central barrier to the promotion of smoking cessation: a survey among general practitioners in Germany, Eur J Public Health, 15, 140-5.

11. (2011) Global status report on alcohol and health (Geneva, World Health Organization).

12. (2010) ATLAS on substance use (2010): Resources for the prevention and treatment of substance use disorders. (Geneva, World Health Organization ).

13. Aveyard, P., Begh, R., Parsons, A. \& West, R. (2012) Brief opportunistic smoking cessation interventions: a systematic review and meta-analysis to compare advice to quit and offer of assistance, Addiction, 107, 1066-73.

14. Stead, L. F., Buitrago, D., Preciado, N. et al. (2013) Physician advice for smoking cessation, Cochrane Database Syst Rev, 5, CD000165.

15. KANER, E. F., BEYER, F., Dickinson, H. O. et al. (2007) Effectiveness of brief alcohol interventions in primary care populations, Cochrane Database Syst Rev, CD004148.

16. Frank, E., Elon, L., NAimi, T. \& Brewer, R. (2008) Alcohol consumption and alcohol counselling behaviour among US medical students: cohort study, BMJ, 337, a2155.

17. Raupach, T., Strobel, L., Beard, E. et al. (2013) German Medical Students' Beliefs About the Effectiveness of Different Methods of Stopping Smoking, Nicotine Tob Res.

18. Krampe, H., Strobel, L., Beard, E. et al. (2013) German Medical Students' Beliefs about How Best to Treat Alcohol Use Disorder, Eur Addict Res, 19, 245-251.

19. Hauer, K. E., CARney, P. A., Chang, A. \& SAtTerfield, J. (2012) Behavior change counseling curricula for medical trainees: a systematic review, Acad Med, 87, 956-68. 